\title{
Insights into the microbial degradation pathways of the ioxynil octanoate herbicide
}

\author{
Karina O. Oliveira ${ }^{\mathrm{a}}$, Amanda R.M. Silva ${ }^{\mathrm{b}}$, Bianca F. da Silva ${ }^{\mathrm{a}}$, Humberto M.S. Milagre ${ }^{\mathrm{a}}$, \\ Cintia D.F. Milagre, ${ }^{\mathrm{a}, *}$
}

a UNESP - São Paulo State University, Institute of Chemistry, Araraquara, 14800-060 SP, Brazil

${ }^{\mathrm{b}}$ USP - University of São Paulo, Institute of Chemistry, São Paulo, 05508-000 SP, Brazil

\section{A R T I C L E I N F O}

\section{Keywords:}

Biodegradation

Ioxynil octanoate

Nitrile hydratase

Amidase

Nitrilase

Dehalogenase

Carbon-carbon lyase

\begin{abstract}
A B S T R A C T
This paper describes the biodegradation of the ioxynil octanoate herbicide by indigenous microorganisms isolated from herbicide impacted soil-enrichment cultures. Eleven positive hits out of twenty-nine microorganisms screened for nitrile hydratase, nitrilase and amidase activity were further evaluated based on their growth in microtiter plates containing liquid medium with increasing concentrations of herbicide (0.97-250 mM). Two strains were selected from this assay for biodegradation studies and were identified as Lysinibacillus boronitolerans MLH-31 and Bacillus cereus MLH-61. The bacterial degradation of ioxynil octanoate and its biodegradation products were monitored, identified and characterized by liquid chromatography tandem mass spectrometry (HPLC-MS/MS). In addition to 3,5-diiodo-4-hydroxybenzamide and 3,5-diiodo-4-hydroxybenzoic acid, which are commonly detected metabolites, two new metabolites were observed: mono-deiodinated compound 3-iodo-4-hydroxybenzoic acid and the product of $\mathrm{C}_{\text {aromatic }} \mathrm{CN}$ cleaved 1,3-diiodophenol. The experimentally observed metabolites were correlated with the enzymatic systems involved, revealing the presence of esterases, nitrile hydratases, amidases, nitrilases, dehalogenases and carbon-carbon lyases during biodegradation. Lysinibacillus boronitolerans MLH-31 was found to degrade ioxynil octanoate at a rate of $97 \%$ over 7 days through a batch-resting cells experiment, while Bacillus cereus MLH-61 was found to do so at a rate of 75\% under the same conditions.
\end{abstract}

\section{Introduction}

By 2050, the world's population will rise from today's 6.8 billion to 9.1 billion according to the latest United Nation projections, and at the same time food demand levels will increase, requiring roughly $70 \%$ more food while land and water resources will remain limited (Food and Agriculture Organization of the United Nations, 2016). To address this issue, a key strategy employed worldwide has involved the use of pesticides. However, the excessive use of pesticides is controversial, as they may threaten food, environmental and rural worker security because such compounds and/or their metabolites can be toxic and persistent to environmental, animal and human health (Holtze et al., 2007a, 2007b). Thus, determining the behaviors of pesticides in the environment and the impacts of these chemical species and their metabolites is of upmost importance and can support their more conscious use.

Benzonitrile herbicides have attracted attention from the scientific community given their global use on several crops since the 1970s to control weed growth in agricultural areas and given that some metabolites are persistent in the environment. High persistency levels of the dichlobenil metabolite 2,6-dichlorobenzamide in European aquifers have led to dichlobenil eradication in several countries, starting with Denmark in 1997 and followed by Brazil in 2002 and all European Union member states in 2011 (Clausen et al., 2006; Holtze et al., 2007a, 2007b; Pukkils et al., 2009; ANVISA, 2002; Rottherdan Convention, 2011). By far, ioxynil degradation is the least studied benzonitrile herbicide and less data are available on ioxynil octanoate (Holtze et al., 2008). Ioxynil and ioxynil octanoate are selective post-emergent contact herbicides used to control broad-leaved weed growth in crops by the inhibition of photosynthesis (Frkova et al., 2014).

The physical and chemical properties of ioxynil octanoate are shown in Table 1 in the Supplementary material. Based on its log P value, it presents hydrophobic rather than hydrophilic features that enable it to penetrate cell membranes and even show potential for

\footnotetext{
* Corresponding author.

E-mail addresses: kaotaoliveira@gmail.com (K.O. Oliveira), amandaribeiroms@yahoo.com.br (A.R.M. Silva), biancafs@iq.unesp.br (B.F. da Silva), humbertomilagre@iq.unesp.br (H.M.S. Milagre), cintiamilagre@iq.unesp.br (C.D.F. Milagre).
} 
<smiles>CCCCCCCC(=O)Oc1c(I)cc(C#N)cc1I</smiles>

<smiles>CCCCCCCC(=O)Oc1c(I)cc(C(=O)O)cc1I</smiles>

$+\mathrm{NH}_{3}$
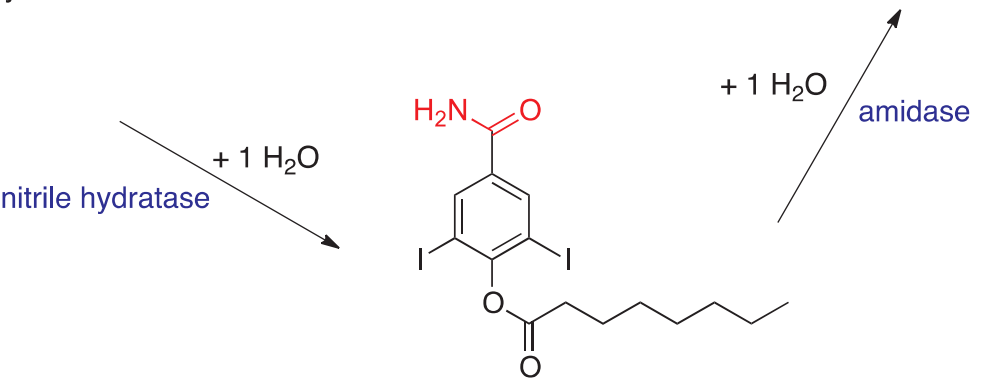

Scheme 1. Main enzymes involved in benzonitrile herbicide biodegradation.

loxynil octanoate<smiles>N#Cc1cc(I)c(O)c(I)c1</smiles>

Fig. 1. Total ion chromatogram (TIC) of ioxynil at $7.23 \mathrm{~min}$ and ioxynil octanoate at $15.15 \mathrm{~min}$.

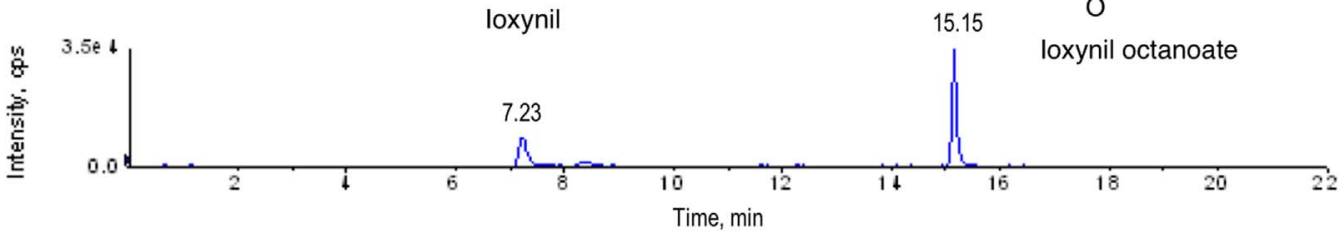

bioaccumulation (European Commission, 2004). In humans, ioxynil has been reported to be a strong inhibitor of thyroid hormone-binding proteins interfering with the thyroid axis and to behave as an endocrine disruptor (Morgado et al., 2007). Moreover, it has been suggested that ioxynil could have moderate cytotoxic effects on two human cell lines (Hep G2 and HEK293T) through the liver and kidneys, respectively and that its amide and carboxylic acid metabolites are less toxic than the parent herbicides (Lovecka et al., 2015). A recent study that identified ioxynil octanoate residue in maize and soil revealed that its use in maize is safe, as no residue was detected at the time of harvesting after 60 days of pesticide treatment (Hu, Dong and Zhen, 2012).

It was observed that the abiotic degradation of benzonitrile herbicides in soils and sediments has minor effects relative to biodegradation (Holtze et al., 2006, 2008; Vesela et al., 2010). The main microbial enzymes responsible for ioxynil biodegradation, as is shown in Scheme 1 , are the enzymes involved in nitrile metabolism: nitrile hydratase (EC 4.2.1.84), amidase (EC 3.5.1.4) and nitrilase (EC 3.5.5.1) (Vesela et al., 2012; Pasquarelli et al., 2015; Detzel et al., 2013; Nielsen et al., 2007, Grab et al., 2000).

Bacteria from the genera Klebsiella, Rhizobium, Variovorax and Pseudomonas are known to effectively degrade ioxynil to the supposedly less toxic metabolites 3,5-diiodo-4-hydroxybenzamide and 3,5-diiodo4-hydroxybenzoic acid (Lovecka et al., 2015). While the complete deiodination of ioxynil to 4-cyanophenol by Desulfitobacterium chlororespirans bacteria has been observed under anaerobic conditions, no dehalogenation products from its correspondent amide and carboxylic acid metabolites have been experimentally observed thus far (Cupples et al., 2005; Holtze et al., 2008). The degradation of ioxynil to $\mathrm{CO}_{2}$ by bacteria has only been described in reference to the Klebsiella strain (Holtze et al., 2008).

The aims of this study are to isolate bacteria of enrichment cultures from ioxynil octanoate exposed soils, to identify potential ioxynil degraders, to monitor the biodegradation of ioxynil octanoate through HPLC-MS/MS batch-resting cell experiments and to correlate the kinetics of experimentally observed metabolites with enzymatic pathways.

\section{Materials and methods}

\subsection{Chemicals}

Analytical grade ioxynil (CAS RN 1689-83-4), ioxynil octanoate (CAS RN 3861-47-0), and isobutyronitrile (CAS RN 78-82-0) were purchased from Sigma-Aldrich (São Paulo, Brazil). Nutrient broth (NB) and Agar were obtained from Acumedia (São Paulo, Brazil). Inorganic salts were purchased from Vetec (São Paulo, Brazil). HPLC grade and analytical solvents were purchased from Panreac (São Paulo, Brazil) and Synth (São Paulo, Brazil), respectively.

\subsection{Microbial collection and isolation of bacteria}

Twenty-nine bacteria strains isolated via the enrichment technique from soils previously exposed to Totril ${ }^{\circ}$ herbicide (active ingredient: ioxynil octanoate) were used in the experiments (strains: MLH-29 to 


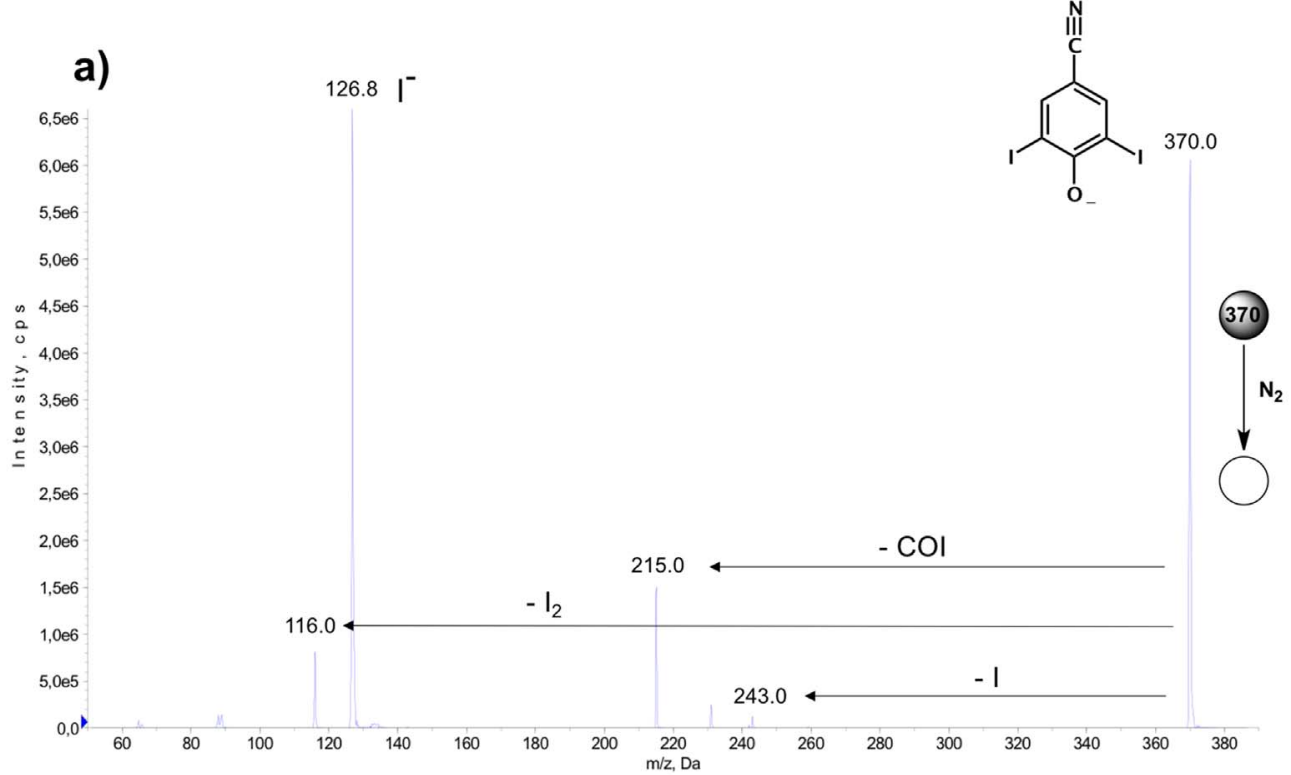

b)

$126.8 \mathrm{I}^{-}$
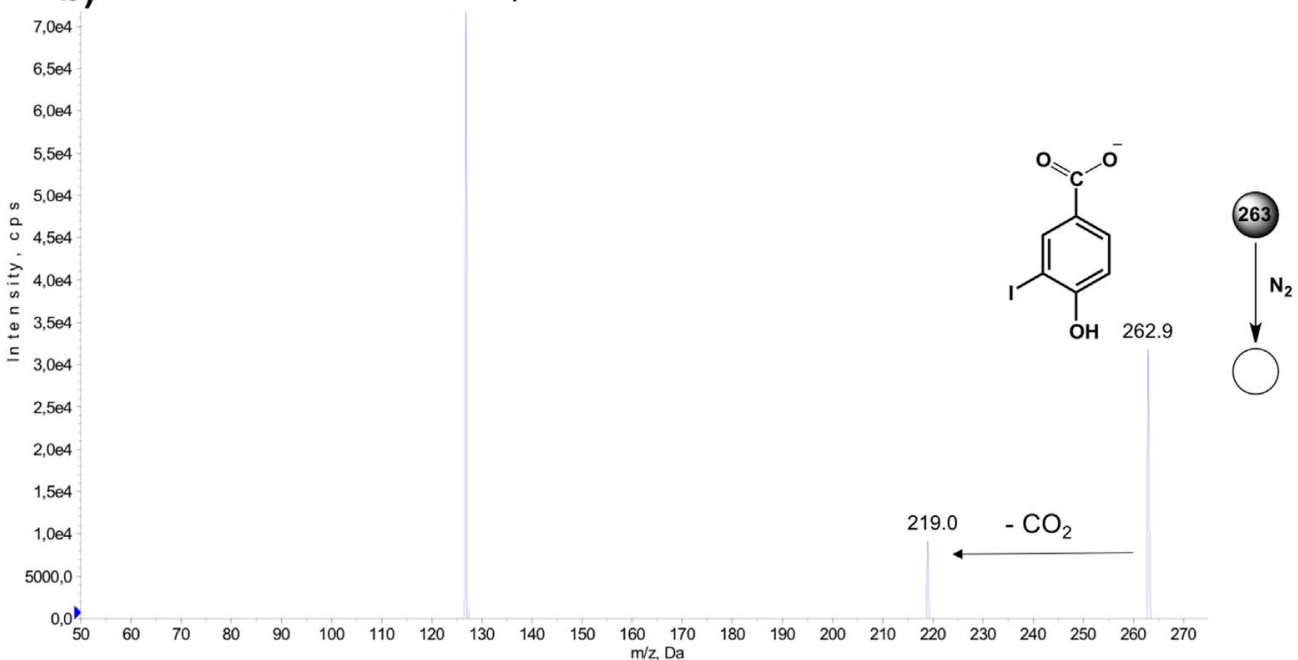

C) $\quad 127.0 \mathrm{I}^{-}$



Fig. 2. ESI-(-)-MS/MS spectra for ions of a) $m / z 370$; b) $m / z ~ 263$; c) $m / z 345$; d) $m / z 388$ and e) $m / z 389$. 

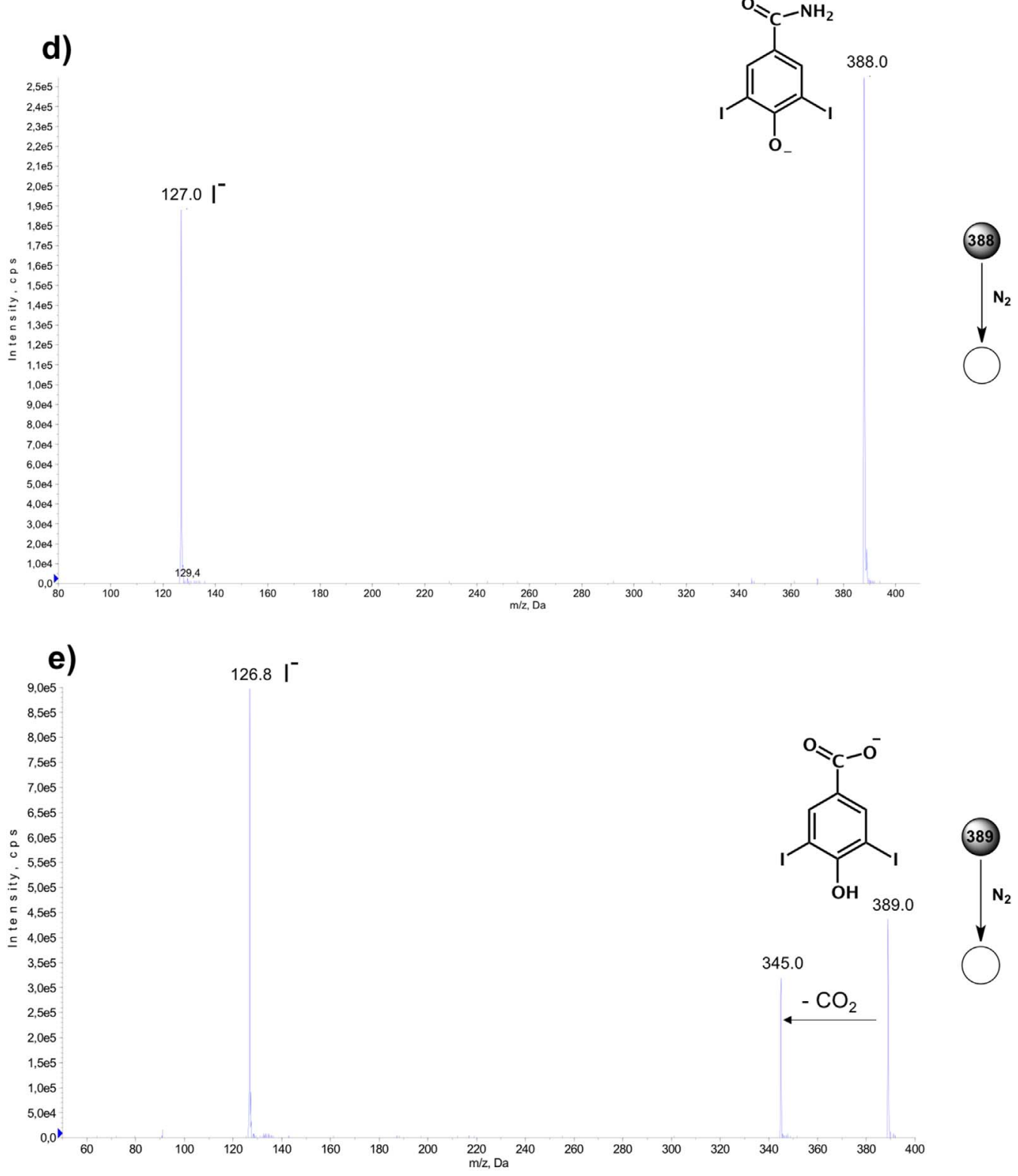

Fig. 2. (continued)

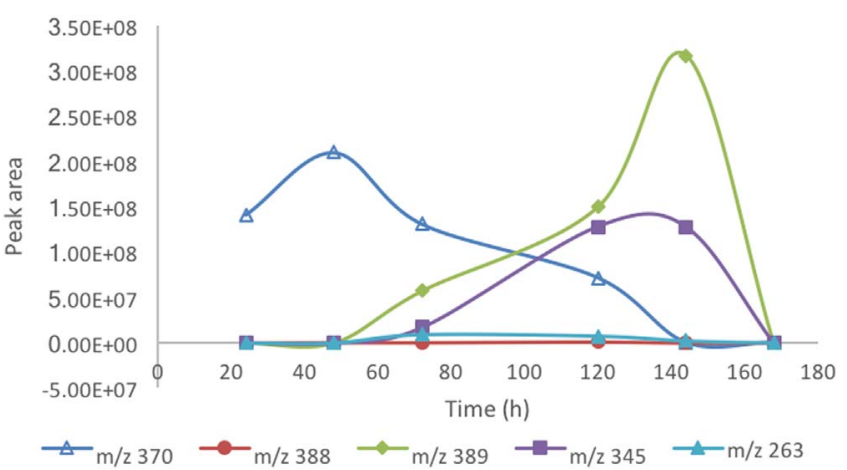

Fig. 3. HPLC-MS/MS monitoring of ioxynil octanoate biodegradation by Lysinibacillus boronitolerans-MLH-31 over 7 days $(168 \mathrm{~h})$.

MLH-40, MLH-42 to MLH-45, MLH-48, MLH-51 to MLH-57, and MLH59 to MLH-63).

A mineral medium containing $\left(\mathrm{g} \mathrm{L}^{-1}\right) \mathrm{FeCl}_{3} \times 6 \mathrm{H}_{2} \mathrm{O}(0.08), \mathrm{CaCl}_{2}$ (0.05), $\mathrm{MgSO}_{4} \times 7 \mathrm{H}_{2} \mathrm{O}(0.02), \mathrm{Na}_{2} \mathrm{HPO}_{4}$ (4.0), $\mathrm{KH}_{2} \mathrm{PO}_{4}$ (2.0) and glucose (1.8) was used for the enrichment culture. After being sterilized, the medium was supplemented with $1 \mathrm{~mL} \mathrm{~L}^{-1}$ trace metal solution, $1 \mathrm{~mL} \mathrm{~L}^{-1}$ vitamin solution and $10 \mathrm{~mL} \mathrm{~L}^{-1}$ Totril $^{\circledast}$. Trace element solution was composed of $\left(\mathrm{g} \mathrm{L}^{-1}\right) \mathrm{MnCl}_{2} \times 1 \mathrm{H}_{2} \mathrm{O}(0.030), \mathrm{NaVO}_{3} \times$ $1 \mathrm{H}_{2} \mathrm{O}$ (0.003), $\mathrm{Na}_{2} \mathrm{WO}_{3} \times 2 \mathrm{H}_{2} \mathrm{O}(0.002), \mathrm{H}_{3} \mathrm{BO}_{3}$ (0.005), $\mathrm{NiSO}_{4} \times$ $6 \mathrm{H}_{2} \mathrm{O}(0.005), \mathrm{ZnSO}_{4} \times 1 \mathrm{H}_{2} \mathrm{O}(0.006), \mathrm{CoCl}_{2} \times 6 \mathrm{H}_{2} \mathrm{O}(0.004)$, $\mathrm{Na}_{2} \mathrm{MoO}_{4} \times 2 \mathrm{H}_{2} \mathrm{O}$ (0.002), $\mathrm{CuSO}_{4}$ (0.003). Vitamin solution was composed of $\left(\mathrm{g} \mathrm{L}^{-1}\right)$ biotin (0.1), calcium pantotenate (0.02), inositol (0.1), nicotinic acid (0.02). Microbial isolation was performed according to Sorokin et al. (2007).

All strains were maintained on nutrient Agar (NA) at $4{ }^{\circ} \mathrm{C}$ and were periodically transferred to a fresh medium (NB). The strains generating better results through biodegradation experiments were characterized via the Sanger sequencing of PCR products of amplified 16S rRNA gene, through outsourced services performed by BPI Genotyping (http:// genotypingbpi.com.br - Botucatu - SP/Brazil). 
<smiles>CCCCCCCC(=O)Oc1c(I)cc(C#N)cc1I</smiles>

loxynil octanoate



Fig. 4. Enzymatic pathways of ioxynil octanoate biodegradation by Lysinibacillus boronitolerans MLH-31 experimentally revealed through the HPLC-MS/MS experiments.

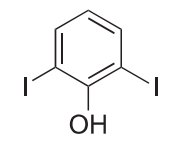

2,6-diiodophenol 3,5-diiodo-4-hydroxybenzonitrile



3,5-diiodo-4-hydroxybenzoic acid

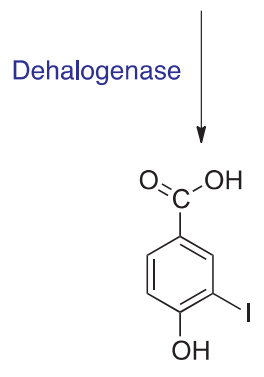

3-iodo-4-hydroxybenzoic acid
2.3. Bacteria cultivation for nitrile hydratase (NHase), amidase and nitrilase (Nase) enzyme assays and for determining maximum inhibitory concentrations of herbicide for microbial growth

Strains were grown in $10 \mathrm{~mL}$ of minimum medium $\left(\mathrm{g} \mathrm{L}^{-1}: 0.08\right.$ $\mathrm{FeCl}_{3} \times 6 \mathrm{H}_{2} \mathrm{O}, 0.05 \mathrm{FeCl}_{2}, 0.02 \mathrm{MgSO}_{4} \times 7 \mathrm{H}_{2} \mathrm{O}, 4.0 \mathrm{Na}_{2} \mathrm{HPO}_{4}, 2.0$ $\mathrm{KH}_{2} \mathrm{PO}_{4}$ and 1.8 glucose), were inducted with $100 \mu \mathrm{L}$ of Totril ${ }^{\circledast}$ ethanolic solution (stock solution $20 \mu \mathrm{L} / \mathrm{mL}$ ) and were incubated for $24 \mathrm{~h}$ at $28^{\circ} \mathrm{C}$ under orbital stirring $(156 \mathrm{rpm})$. Then, cells were harvested by centrifugation for $10 \mathrm{~min}$ at $3000 \mathrm{rpm}$ and at $60 \mathrm{~m} / \mathrm{s}^{2}$. The supernatant was discarded and the biomass was rinsed and resuspended in phosphate buffer ( $\mathrm{pH} 7.2,10 \mathrm{mM}$ ) to reach a final cellular concentration of $200 \mathrm{mg} \mathrm{mL}^{-1}$.

\subsection{Nitrile hydratase (NHase), amidase and nitrilase (Nase) enzyme assays}

Enzyme assays for nitrile hydratase, amidase and nitrilase were performed according to Angelini et al. (2015).

\subsection{Experiments for determining the maximum inhibitory concentration of herbicide for microbial growth}

In a 96-well microtiter plate, a serial dilution of aqueous buffered solution (pH 7.2, $10 \mathrm{mM}$ ) with $250 \mathrm{mM}$ of Totril ${ }^{\circledR}$ solution was performed to achieve final concentrations of $0.97,1.95,3.90,7.80,15.6$, $31.3,62.5,125$ and $250 \mathrm{mM}$ in a volume of $100 \mu \mathrm{L}$. Then, $100 \mu \mathrm{L}$ of NB media containing cell suspensions $\left(200 \mathrm{mg} \mathrm{mL}^{-1}\right.$ ) was added to each well. Microtiter plates were incubated under orbital stirring (181 rpm) at $29{ }^{\circ} \mathrm{C}$. After $24 \mathrm{~h}, 100 \mu \mathrm{L}$ of MTT $0.025 \%$ was added to each well and the microtiter plate was incubated again for $1 \mathrm{~h}$. Cell viability levels were measured by the visual inspection of the microtiter plate. A color change from yellow to purple denotes the occurrence of mitochondrial respiration and consequently cell viability. All of the assays and microbial control experiments were performed in duplicate.

\subsection{Biodegradation experiments}

\subsubsection{Pre-inoculum preparation}

Strains were grown in 1-L Erlenmeyer flasks with $350 \mathrm{~mL}$ of $\mathrm{NB}$ medium, glucose $\left(10 \mathrm{~g} \mathrm{~L}^{-1}\right)$ and yeast extract $\left(1 \mathrm{~g} \mathrm{~L}^{-1}\right)$ at $28{ }^{\circ} \mathrm{C}$ under $156 \mathrm{rpm}$ for $24 \mathrm{~h}$.

\subsubsection{Enzymatic induction}

It were transferred $8 \%$ of the pre-inoculum to a $500 \mathrm{~mL}$-Erlenmeyer flask containing $250 \mathrm{~mL}$ of induction medium $\left(\mathrm{NaH}_{2} \mathrm{PO}_{4} \times \mathrm{H}_{2} \mathrm{O}\right.$ $1.03 \mathrm{~g} \mathrm{~L}^{-1}, \mathrm{KHPO}_{4} 2.0 \mathrm{~g} \mathrm{~L}^{-1}, \mathrm{MgSO}_{4} \times 7 \mathrm{H}_{2} \mathrm{O} 0.50 \mathrm{~g} \mathrm{~L}^{-1}, \mathrm{FeSO}_{4} \times$ $7 \mathrm{H}_{2} \mathrm{O} 0.03 \mathrm{~g} \mathrm{~L}^{-1}, \mathrm{CaCl}_{2} 0.05 \mathrm{~g} \mathrm{~L}^{-1}$, yeast extract $0.10 \mathrm{~g} \mathrm{~L}^{-1}$, glucose $10 \mathrm{~g} \mathrm{~L}^{-1}, \mathrm{CoCl}_{2} \times 6 \mathrm{H}_{2} \mathrm{O} 0.05 \mathrm{~g} \mathrm{~L}^{-1}$ and isobutyronitrile $(55 \mathrm{mM}$ solubilized in $2.5 \mathrm{~mL}$ ethanol) and we stirred under orbital conditions (156 rpm) at $28^{\circ} \mathrm{C}$ for $24 \mathrm{~h}$.

\subsubsection{Biodegradation experiments}

The resulting biomass from the enzymatic induction was harvested by centrifugation (10 $\mathrm{min}, 3000 \mathrm{rpm}$, and $\left.60 \mathrm{~m} / \mathrm{s}^{2}\right)$ and was rinsed and re-suspended in phosphate buffer $(100 \mathrm{mM}, \mathrm{pH} 7.5)$ to achieve $\mathrm{OD}_{610}$ $=2$. It was added Totril ${ }^{\circledR}$ to this mixture $(0.1 \mathrm{mM}$ solubilized in $4.5 \mathrm{~mL}$ of ethanol). The biotransformation reaction was facilitated under 
orbital stirring at $28^{\circ} \mathrm{C}$ and was monitored by HPLC-MS/MS for 7 days. Microbial and substrate control experiments were performed in parallel.

\subsection{HPLC-MS/MS analysis}

Analyses were performed using a AB SCIEX 3200 QTRAP HPLC-MS/ MS and the analytes were separated on a Kinetex C18 (150 mm $\times$ $4.6 \mathrm{~mm}, 5 \mu \mathrm{m}$ particle size) at $40{ }^{\circ} \mathrm{C}$. Gradient elution was applied in binary solvent system water: acetonitrile: $0.0-0.5 \mathrm{~min}$ (10\% acetonitrile), $0.5-14.0 \mathrm{~min}$ ( $100 \%$ acetonitrile), $14.0-17.0$ (100\% acetonitrile), 17.0-17.5 (10\% acetonitrile), and $17.5-22.0 \mathrm{~min}$ (10\% acetonitrile). The flow rate was set to $1000 \mu \mathrm{L} \mathrm{min}^{-1}$ and aliquots diluted in methanol were drawn through biodegradation experiments $(20 \mu \mathrm{L})$ : water (1000:1).

Electrospray ionization (turbo ion spray source) was applied in the negative mode (ESI-(-)) for all of the compounds, and a mass analysis was performed to scan ions in the enhanced mode (EMS, enhanced mass scan) using a linear ion trap analyzer. The ion source parameters were as follows: ion spray $4500 \mathrm{~V}$, temperature $550{ }^{\circ} \mathrm{C}$, gas $145 \mathrm{psi}$, gas 2 $45 \mathrm{psi}$, curtain gas $12 \mathrm{psi}$, declustering potential $40 \mathrm{~V}$, and entrance potential $11 \mathrm{~V}$. Ion fragment experiments (EPI, enhanced product) were also performed using a liner ion trap to obtain more structural information. Collision energy levels ranged from 25 to $50 \mathrm{~V}$.

\section{Results and discussion}

\subsection{Screening of bacterial degraders}

Indigenous bacteria were isolated from the enrichment cultures of soil currently exposed to Totril ${ }^{\circledR}$, a commercial formulation of ioxynil octanoate formulated by the Bayer company. The enrichment culture yielded 29 bacterial isolates of the following codes: MLH-29 to MLH-40, MLH-42 to MLH-45, MLH-48, MLH-51 to MLH-57, and MLH-59 to MLH-63. The first screening evaluated the presence of enzymes of nitrile metabolism through a colorimetric assay (Angelini et al., 2015). This was found because nitrile hydratase (EC 4.2.84.1), amidase (EC 5.5.1.4) and nitrilase (EC 3.5.5.1) are well known for taking part in benzonitrile herbicide biodegradation, yielding the respective amides and/or carboxylic acids from nitrile (Scheme 1). Among them, 11 strains (MLH- 31, 34, 36, 42, 43, 54, 55, 59, 60, 61 and 63) were selected.

The next step involved determining the maximum concentration of ioxynil octanoate that did not inhibit microbial growth. A MTT (3-(4,5dimethylthiazol-2-yl)-2,5-diphenyltetrazolium bromide) assay was performed to evaluate cell viability levels against increasing herbicide concentrations $(0.97,1.95,3.90,7.80,15.6,31.3,62.5,125$ and $250 \mathrm{mM})$. Cell viability levels were measured by visual inspecting the microtiter plate. Color changes from yellow tetrazole (MTT) to purple formazan denote mitochondrial respiration and thus cell viability (Table 2, Supplementary Material). From this MTT-assay, strains MLH31 and MLH-61 were selected for the biodegradation experiments. A concentration of $15.6 \mathrm{mM}$ was found to be 31 times higher than ioxynil octanoate concentrations found in the soil that the microorganisms were isolated from. The two strains were identified by Sanger sequencing: MLH-31 presented $100 \%$ similarity with Lysinibacillus boronitolerans while MLH-61 presented 99\% similarity with Bacillus cereus.

\subsection{Biodegradation experiments and HPLC-MS/MS monitoring}

Biodegradation products were monitored, identified and characterized by HPLC-MS/MS analysis. Tandem mass spectrometry ESI-MS (/MS) has been established as the main approach to reaction monitoring. The technique is used to with sensitivity and gentleness "fish out" ionic and ionized intermediates directly from reaction solutions into the gas phase, in which proper characterization using a variety of
MS techniques can be performed (Vaz et al., 2013). A batch-resting cells experiment in phosphate buffer $(\mathrm{pH} 7.2,100 \mathrm{mM})$ and Totril ${ }^{\oplus}(1.0 \mathrm{mM})$ with pre-induced strains of Lysinibacillus boronitolerans MLH-31 and Bacillus cereus MLH-61 $\left(\mathrm{OD}_{600}=2.0\right)$ at $28^{\circ} \mathrm{C}$ under orbital stirring (156 rpm) protected from light was performed to evaluate herbicide biodegradation. Each sample was centrifuged, supernatant was diluted in methanol: water solution (1000: 1) and it was directly analyzed by HPLC-MS/MS. In parallel, substrate stability and microbial control experiments were performed. It is well known that ioxynil octanoate easily undergoes ester hydrolysis in alkaline medium and that its C-halogen bond can be photohydrolyzed in aqueous solution (Holtze et al., 2008; Malouki et al., 2004). Our substrate stability experiments show that no abiotic degradation or phototransformation occurred under the experimental conditions used. In our microbial control experiments, no ioxynil octanoate biodegradation products or metabolites were observed.

The chromatographic method was applied to a sample of Totril ${ }^{\varpi}$. The chromatogram revealed the presence of active ingredient ioxynil octanoate (MW $497 \mathrm{~g} \mathrm{~mol}^{-1}$; retention time $15.15 \mathrm{~min}$ ) and of minor concentrations of ioxynil (MW $371 \mathrm{~g} \mathrm{~mol}^{-1}$; retention time $7.23 \mathrm{~min}$ ) besides hydrocarbon solvents. Standard commercial samples of ioxynil and ioxynil octanoate were also analyzed to confirm compound retention times and fragmentation patterns. An HPLC-ESI-(-)-MS analysis of both ioxynil and ioxynil octanoate standard samples revealed the presence of ions of $m / z 370$ corresponding to deprotonated species $[\mathrm{M}-\mathrm{H}]$ and $\left[\mathrm{M}-\mathrm{C}_{8} \mathrm{H}_{16} \mathrm{O}\right]^{-}$, respectively, as is shown in Fig. 1 . These results denote the presence of an ester cleavage in the ion source.

Ester cleavage in the mass spectrometer ion source and enzyme hydrolytic activity were studied using HPLC peak areas drawn from the substrate control and biodegradation experiments. It was assumed that the decrease in the chromatographic peak area of ion $\mathrm{m} / \mathrm{z} 370$ at 15.15 min identified from the biodegradation experiments denoted the presence of hydrolases responsible for enzymatic ester cleavage.

During biodegradation monitoring, four major ions of $m / z 263,345$, 388 and 389 were easily and directly intercepted and further characterized via ESI-(-)-MS/MS (Fig. 2). Ions of $m / z 388$ and 389 were characterized as deprotonated ioxynil amide and carboxylic acid, respectively. It was found that the ion of $\mathrm{m} / \mathrm{z} 345$ corresponds to the deprotonated product of the $\mathrm{C}_{\text {aromatic }}-\mathrm{C}_{\text {carboxylic acid }}$ cleavage while the ion of $m / z 263$ corresponds to deprotonated mono-deiodinated carboxylic acid.

Kinetics of the biodegradation of ioxynil octanoate by Lysinibacillus boronitolerans MLH-31 are shown in Fig. 3. After $24 \mathrm{~h}$, the product of ester hydrolysis appears as a primary metabolite (ion of $m / z$ 370) followed by the correspondent amide (ion of $m / z$ 388). These results denote the presence of enzymes hydrolase and nitrile hydratase, respectively, during the first phase of ioxynil octanoate biodegradation. The ion of $m / z 370$ reached maximum intensity levels within $48 \mathrm{~h}$ and then decreased for up to $144 \mathrm{~h}$, after which it was no longer observed. No accumulation of amide occurred (ion of $m / z$ 388) throughout the process, indicating that this metabolite was continuously biodegraded by an amidase, leading to the generation of the corresponding carboxylic acid (ion of $m / z 389$ ). After $48 \mathrm{~h}$, the ion $m / z 389$ appeared and expanded at a higher rate than the others, and likely due to the simultaneous actions of two enzymes that can lead to the formation of carboxylic acid: a nitrilase that uses the ioxynil as a substrate and the amidase which uses the recently and continuously formed amide. Between 48 and $72 \mathrm{~h}, \mathrm{~m} / \mathrm{z} 263$ ions (mono-deiodinated product) appear, denoting the presence of a dehalogenase. The last metabolite is observed after $48 \mathrm{~h}$ and corresponds to the ion of $\mathrm{m} / \mathrm{z} 345$ originating from the action of carbon-carbon lyase responsible for the cleavage of a $\mathrm{C}_{\text {aromatic }}-\mathrm{C}_{\text {carboxylic acid }}$ bond, suggesting that the main substrate of this enzyme is carboxylic acid. After $168 \mathrm{~h}$, none of the mentioned metabolites were observed any longer.

Based on the HPLC-MS/MS results, we propose the ioxynil octanoate biodegradation pathways shown in Fig. 4 . 
According to the literature, ioxynil was biodegraded to the corresponding carboxylic acid at a rate of $40 \%$ after $168 \mathrm{~h}$ (7 days) by Aminobacter MSH1 $\left(\mathrm{OD}_{600} \sim 1\right)$ while Rhodococcus rhodochrous PA-34, Rhodococcus sp. NDB 1165 and Nocardia globerula NHB-2 $\left(\mathrm{OD}_{600} \sim 2\right.$ for all three strains) degraded ioxynil into its correspondent carboxylic acid at a rate of $60 \%$ over $20 \mathrm{~h}$, and no further degradation was observed over 3 days. Through a batch-resting cell experiment, a rate of $97 \%$ ioxynil octanoate biodegradation by the bacteria Lysinibacillus boronitolerans $\mathrm{MLH}-31\left(\mathrm{OD}_{600} \sim 2\right)$, an indigenous strain isolated from ioxynil octanoate-exposed soil, was achieved over $168 \mathrm{~h}$ (7 days). The Bacillus cereus MLH-61 $\left(\mathrm{OD}_{600} \sim 2\right)$ strain degraded $75 \%$ of the ioxynil octanoate within 7 days through a similar pattern of enzymatic degradation though distinct kinetic behaviors (data not shown).

\section{Conclusion}

This paper sheds light on the biodegradation pathways of ioxynil octanoate by Gram-positive bacteria Lysinibacillus boronitolerans MLH31. This investigation suggests that hydrolases are the first enzymes acting in the enzymatic cascade, yielding the active ingredient ioxynil. Nitrile hydratases then convert it to the less toxic amide, the substrate of amidase which immediately hydrolyzes it into the corresponding carboxylic acid. Carboxylic acid can also be directly obtained from nitrilases. Moreover, this carboxylic acid suffers from reductive monodeiodination catalyzed by dehalogenases and a simultaneous $\mathrm{C}_{\text {aromatic }}{ }^{-}$ $\mathrm{C}_{\text {carboxylic acid }}$ bond cleavage catalyzed by lyases. This is the first report to elaborate on Lysinibacillus boronitolerans bacteria as an ioxynil octanoate degrader. The two new observed biodegradation metabolites (3-iodo-4-hydroxybenzoic acid and 1,3-diiodophenol) were also included in the herbicide pathway. In addition, Lysinibacillus boronitolerans can biodegrade ioxynil octanoate over a shorter period than other bacteria described in the literature, revealing its potential as a benzonitrile herbicide degrader. Experiments with pilot plants simulating natural conditions should be done to explore the behavior of ioxynil octanoate degradation under natural field conditions by this microorganism.

\section{Acknowledgements}

The present work was financially supported through the São Paulo Research Foundation - FAPESP (Grant nos. 2010/02305-5, 2011/ 00014-4 and 2014/50249-8), CNPq (Grant nos. 560682/2010-7 and 384996/2012-4) and Portal de Periódicos CAPES.

\section{Appendix A. Supplementary material}

Supplementary data associated with this article can be found in the online version at http://dx.doi.org/10.1016/j.bcab.2018.01.002.

\section{References}

ANVISA, 2002. Resolução RDC no. 347 de 16 de dezembro de 2002.

Angelini, L.M.L., Silva, A.R.M., Rocco, L.F.C., Milagre, C.D.F., 2015. A high-throughput screening assay for distinguishing nitrile hydratases from nitrilases. Braz. J. Microbiol. 46, 113-115.

Clausen, L., Arildskov, N.P., Larsen, F., Aamand, J., Albrechtsen, H.-J., 2006. Degradation of the herbicide dichlobenil and its metabolite BAM in soils and surface sediments. J. Contam. Hydrol. 89, 157-173.

Cupples, A.M., Sanford, R.A., Sims, G.K., 2005. Dehalogenation of the herbicides bromoxynil (3,5-dibromo-4-hydroxybenzonitrile) and ioxynil (3,5-diiodino-4- hydroxybenzonitrile) by Desulfitobacterium chlororespirans. Appl. Environ. Microbiol. $71,3741-3743$.

Detzel, C., Maas, R., Tubeleviciute, A., Jose, J., 2013. Autodisplay of nitrilase from Klebsiella pneumoniae and whole-cell degradation of oxynil herbicides and related compounds. Appl. Microbiol. Biotechnol. 97, 4887-4896.

European Commission. Health \& Consumer Protection Directorate-E1 - Plant Health. Ioxynil. SANCO/4349/2000 final. Review report for the active substance ioxynil. Finalised in the Standing Committee on the Food Chain and Animal Health at is meeting on 13 February 2004 in view of the inclusion of ioxynil in Annex I of Directive 91/414/EEC. Available: 〈http://ec.europa.eu/food/plant/pesticides/eupesticides-database/public $/$ ? event $=$ activesubstance detail\&language $=\mathrm{EN} \&$ selectedID $=1480>$ (Accessed 16 July 2016).

Food and Agriculture Organization of the United Nations: High Level Expert Forum - How to Feed in 2050, Global Agriculture Towards 2050. Available: 〈http://www.fao.org/ news/story/en/item/35571/icode/2016〉 (Accessed 16 July 2016).

Frkova, S., Badawi, N., Johansem, A., Schultz-Jensen, N., Bester, K., Sorensen, S.R., Karlson, U.G., 2014. Degradation of three benzonitrile herbicides by Aminobacter MSH1 versus soil microbial communities: pathways and kinetics. Pest. Manag. Sci. 70, 1291-1298.

Grab, B., Mayer, H., Nolte, J., Preub, G., Zullei-Seibert, N., 2000. Studies on the metabolism of hydroxybenzonitrile herbicides: I. Mass spectrometric identification. Pest. Manag. Sci. 56, 49-59.

Holtze, M.S., Sorensen, J., Christian, H., Aamand, J., 2006. Transformation of the herbicide 2,6-dichlorobenzonitrile to the persistent metabolite 2,6-dichorobenzamide (BAM) by soil bacteria known to harbor nitrile hydratase or nitrilase. Biodegradation 17, 503-510.

Holtze, M.S., Sorensen, S.R., Sorensen, J., Hansen, H.C.B., Aamand, J., 2007a Biostimulation and enrichment of 2,6-dichlorobenzmide-mineralizing soil bacterial communities from dichlobenil-exposed soil. Soil Biol. Biochem. 39, 216-223.

Holtze, M.S., Hansen, H.C.B., Juhler, R.K., Sorensen, J., Aamand, J., 2007b. Microbial degradation pathways of the herbicide dichlobenil in soils with different history of dichlobenil-exposure. Environ. Pollut. 148, 343-351.

Holtze, M.S., Sorensen, S.R., Sorensen, J., Hansen, H.C., Aamand, J., 2008. Microbial degradation of the benzonitrile herbicides dichlobenil, bromoxynil and ioxynil in soil and surface environments - Insights into degradation pathways, persistent metabolites and involved degrader organisms. Environ. Pollut. 154, 155-168.

Hu, J.Y., Dong, B.Z., Zhen, Z.H., 2012. Residue determination and dissipation of ioxynil octanoate in maize and soil. J. Environ. Sci. Health B 47, 385-389.

Lovecka, P., Thimova, M., Grznarova, P., Lipov, J., Knejzlik, Z., Stiborova, H., Nindhia, T.G.T., Demnerova, K., Ruml, T., 2015. Study of cytotoxic effects of benzonitrile pesticides. BioMed. Res. Int (article number 381264, 9 pages).

Malouki, M.A., Zertal, A., Lavédrine, B., Sehili, T., Boule, P., 2004. Phototransformation of 3,5-dihalogeno-4-hydroxybenzonitriles (ioxynil and chloroxynil) in aqueous solution. J. Photochem. Photobiol. A 168, 15-22.

Morgado, I., Hamers, T., Van der Ven, L., Power, D.M., 2007. Disruption of thyroid hormone binding to sea bream recombinant transthyretin by ioxynil and polybrominated diphenyl ethers. Chemosphere 69, 155-163.

Nielsen, M.K.K., Holtze, M.S., Svensmark, B., Juhler, R., 2007. Demonstrating formation of potentially persistent transformation products from the herbicides bromoxynil and ioxynil using liquid chromatography-tandem mass spectrometry (LC-MS/MS). Pest. Manag. Sci. 63, 141-149.

Pasquarelli, F., Spera, A., Cantarella, L., Cantarella, M., 2015. Biodegradation of bromoxynil using the cascade enzymatic system nitrile hydratase/amidase from Microbacterium imperiale CBS 498-74. Comparison between free enzymes and resting cells. RSC Adv. 5, 36913-36923.

Pukkils, V., Gustafsson, J., Tuominen, J., Aallonen, A., Kontro, M.H., 2009. The mostprobable number enumeration of dichlobenil and 2,6-dichlorobenzamide (BAM) degrading microbes in Finnish aquifers. Biodegradation 20, 679-686.

Rottherdan Convention, 2011. Notification of final regulatory action to ban dichlobenil. Available: 〈http://ec.europa.eu/transparency/regexpert/index.cfm?Do = groupDetail.groupDetailDoc\&id $=6570 \&$ no $=10>$ (Accessed 12 July 2016).

Sorokin, D.Y, van Pelt, S., Tourova, T.P., Muyzer, G., 2007. Microbial isobutyronitrile utilization under haloalkaline conditions. Appl. Environ. Microbiol. 73, 5574-5579.

Vaz, B.G., Milagre, C.D.F., Eberlin, M.N., Milagre, H.M.S., 2013. Shvo's catalyst in chemoenzymatic dynamic kinetic resolution of amines - inner or outer sphere mechanism? Org. Biomol. Chem. 11, 6695-6698.

Vesela, A.B., Franc, M., Pelantova, H., Kubac, D., Vejvoda, A., Sulc, M., Bhalla, T.C., Mackova, M., Lovecka, P., Janu, P., Demnerova, K., Martinkova, L., 2010. Hydrolysis of benzonitrile herbicides by soil actinobacteria and metabolite toxicity. Biodegradation 21, 761-770.

Vesela, A.B., Pelantova, H., Sulc, M., Mackova, M., Lovecka, P., Thimova, M., Pasquarelli, F., Picmanova, M., Patek, M., Bhalla, T.C., Martinkova, L., 2012. Biotransformation of benzonitrile herbicides via the nitrile hydratase-amidase pathway in Rhodococci. J. Ind. Microbiol. Biotechnol. 39, 1811-1819. 